\title{
On signaling pathways: hematopoietic stem cell specification from hemogenic endothelium
}

\author{
LONG Yan \& HUANG He* \\ Bone Marrow Transplantation Center, The First Affiliated Hospital, School of Medicine, Zhejiang University, Hangzhou 310003, China
}

Received August 22, 2015; accepted October 16, 2015; published online November 25, 2015

\begin{abstract}
Hematopoietic stem cells (HSCs) are specified and generated during the embryonic development and have remarkable potential to replenish the full set of blood cell lineages. Researchers have long been interested in clarifying the molecular events involved in HSC specification. Many studies have reported the development of methods for generating functional hematopoietic cells from pluripotent stem cells (PSCs-embryonic stem cells (ESCs) and induced pluripotent stem cells (iPSCs)) for decades. However, the generation of HSCs with robust long-term repopulation potential remains a swingeing challenge, of which a major factor contributing to this failure is the difficulty to define the intraembryonic signals related to the specification of HSCs. Since HSCs directly derive from hemogenic endothelium, in this review, we summarize both in vivo and in vitro studies on conserved signaling pathways that control the specification of HSCs from hemogenic endothelial cells.
\end{abstract}

HSCs, hemogenic endothelium, signaling pathways

Citation: Long Y, Huang H. On signaling pathways: hematopoietic stem cells specification from hemogenic endothelium. Sci China Life Sci, 2015, 58: 1256-1261, doi: 10.1007/s11427-015-4976-3

Hematopoietic stem cells (HSCs) emerge in the definitive hematopoiesis of early embryos. Definitive hematopoiesis initiates through the formation of transient erythromyeloid progenitors (EMPs), then the HSCs arise. EMPs and HSCs not only share many phenotypic traits, but also both have multilineage potential. Typically, they can be distinguished by their lymphoid potential or self-renewal capacity, as well as the Notch signal profile [1]. From the anatomy level, evidences provided by in vitro studies have demonstrated that HSCs specification can be detected in various embryonic sites, including umbilical and vitelline arteries [2], the placenta [3], the fetal head [4] and the yolk sac [5]. From cell level, HSCs fate has been determined from formation of the primitive steak as the beginning, then followed by initiation of hemangioblasts, hemogenic endothelium and HSCs in the end $[6,7]$. Along the passage of embryonic definitive hematopoiesis, the signaling environment plays a major role in

*Corresponding author (email: huanghe@ zju.edu.cn) governing HSCs fate.

\section{The general route of developmental events of HSCs}

In early embryos, HSCs develop from the ventro-posterior floor of the lateral plate mesoderm and the first definitive HSCs are detected in the aorta-gonad-mesonephros (AGM) region in mouse E10.5 embryos [8]. The earliest hematopoietic mesoderm cells, which display both hematopoietic and vascular potential, were first identified in the de novo embryoid body (EB) forming system [9]. Signaling pathways that control posterior mesoderm specification are distinctive and include bone morphogenetic protein (BMP) [10], fibroblast growth factor (FGF) [11], Nodal [12] and Wnt [13].

The second step of HSCs development is the formation of hemogenic endothelium, which control HSCs fate via an 
endothelial-hematopoietic transition process confirmed in mouse studies [14]. The concept of hemogenic endothelium was initially developed based on AGM studies, and later it was proved to exist in varied embryonic and extraembryonic sites, including umbilical arteries [15], the placenta [3], the head [4] and nascent yolk sac capillaries [16]. A mouse study found that hemogenic endothelial cells are retinoic acid (RA) responsive, and defined several critical signals downstream RA, including c-Kit, Notch and p27 that are required for hemogenic endothelium specification [17].

The final step is the specification of HSCs from hemogenic endothelium. It seems to exist transiently and is characterized by changes in gene expression and shape of ventral aortic endothelial cells [1]. In order to clarify the trigger signals of this process, the identification of direct precursors of HSCs is crucial. Recent studies on HSCs fate determination demonstrate that the transition of both primitive and definitive program are from $\mathrm{CD} 34^{+} \mathrm{CD} 43^{-}$hemogenic endothelial cells, while the difference is that only $\mathrm{KDR}^{+}$ $\mathrm{CD} 235 \mathrm{a}^{-}$mesodermal cells derived $\mathrm{CD} 34^{+} \mathrm{CD} 43^{-}$population give rise to definitive HSCs compared to the $\mathrm{KDR}^{+} \mathrm{CD} 235 \mathrm{a}^{+}$mesodermal cells $[18,19]$. Thus, it is challenging to distinguish definitive hemogenic endothelium from the differentiated clusters only on the basis of cell surface markers, therefore more molecular details are required to unveil the emergence of direct precursors of HSCs. Classical signaling pathways related to the commitment of HSCs from hemogenic endothelium include Sonic hedgehog (Shh) [20], Notch [21],VEGF [22], and Wnt [23].

\section{The accumulating data of different signaling patterns of HSCs fate determination from hemogenic endothelium}

Studies have provided direct evidence that the formation of HSCs from hemogenic endothelium involved endothelial-hematopoietic transition (EHT) [24]. This process depends strictly on the balance of intrinsic and extrinsic molecular signals [25]. Here, we list current knowledge of intraembryonic signaling pathways that control HSCs fate determination from hemogenic endothelium.

\subsection{Notch signaling}

Notch signaling is highly conserved across the metazoan [26]. In mammals, there are at least 5 Notch ligands (Jagged1, Jagged3, Delta1, Delta3 and Delta4) interacting with transmembrane receptors (Notch1, Notch2, Notch3, and Notch4 in mice; Notch1a, Notch1b, Notch2, and Notch3 in zebrafish) on adjacent cells, leading to activation of Notch signaling by liberation of the Notch intracellular domain (NICD). Released NCID translocates into the nucleus and modulates target gene expression [27].

Notch signaling is required for vascular patterning, HSC specification and cell fate determination of blood cells. The endothelial-hematopoietic transition also displays a Notch-dependent manner. Both in vivo and in vitro studies have manifested that the requirement for Notch1 is vital and cell-autonomous in the establishment of HSCs, moreover disturb of notch signaling pathway in vivo directly led to loss or decrease of HSCs [28,29]. The Notch $1^{-/}$embryo displayed a severely impaired hematopoietic cell development but had no cell number decrease in hemogenic endothelial cells [30], and the Notch $1^{-/-}$mouse embryonic stem cells kept the capacity to differentiate into flk1 mesodermal cells but failed in produce HSCs [31]. Inactivated Notch signaling in zebrafish had no effects on vascular function, meanwhile dose-dependent activation of Notch signal led to considerable expansion of HSCs without any change of some arterial markers, which manifested that Notch signaling acts through independent pathways to regulate induction of each cells fate [28]. Notch1a and Notch1b, two orthologues of Notch1, are both required autonomously in hemogenic endothelium for HSC generation, meanwhile, Notch3 is proved to function in a non-cell-autonomous manner [32]. Jagged1 knockout mice had decreased number of Gata2 and Runx1 expressing HSCs in the E10.5 embryo compared with the normal ones, but it remained normal arterial formation, suggesting unique Notch requirements between HSCs and arterial fate [33]. Notch1 activates downstream Runxl gene expression indirectly through Gata2, which is required in definitive hematopoiesis from endothelial cells [30]. Meanwhile Notch1 acts via Foxc2 in hemogenic endothelium to promote definitive hematopoiesis [21]. However, more Notch-regulated elements controlling HSC generation need to be discovered, such as the unique targets downstream of each required Notch receptors that dominates specification of HSCs.

\subsection{Wnt/ $\beta$-catenin signaling}

The signaling contains Wnt proteins, which involves at least 19 highly conserved secreted glycoproteins function as ligands, $10 \mathrm{G}$ protein-coupled Frizzled (Fzd) receptors and 2 low-density lipoprotein receptor-related proteins (LRP) coreceptors [34]. The canonical Wnt pathway involves two core components, which are $\beta$-catenin and members of the $\mathrm{T}$ cell factor (TCF)/lymphocyte enhancer binding factor (LEF) transcriptional factor family [35]. Wnt ligands bind to the receptor complex, activate the pathway by elevating cytoplasmic level of $\beta$-catenin, then migrate to the nucleus and bind to TCF/LEF transcription factor, thereby activating the transcription of target genes [36,37].

$\mathrm{Wnt} / \beta$-catenin controls many biological processes, including cell fate determination, cell proliferation and self-renew. The role of certaining Wnt proteins in HSC specification has remained elusive. Wnt $3 \alpha$-knockout mice had decreased numbers of HSCs and an impaired reconstruction ability in the secondary transplantation assay [38]. Another mouse study shown that Wnt $3 \alpha$ deficiency 
did not significantly influence the expression of the other Wnt genes, and Wnt $3 \alpha^{-1-}$ LSKs displayed a complete abolishment of canonical Wnt signaling, based on which we can speculate that Wnt $3 \alpha$ might be the only Wnt protein able to activate canonical Wnt signaling in the HSCs [39]. However, direct effects of Wnt3a on the specification of HSCs from hemogenic endothelium have not been reported. Activation of $\beta$-catenin was shown to be vital for HSC specification in the zebrafish AGM through a cyclic AMP (cAMP)/protein kinase A (PKA)-dependent mechanism downstream of prostaglandin E2 (PGE2) [40]. The same result were found in mice that $\mathrm{Wnt} / \beta$-catenin activity was restricted to a very small number of endothelial cells in the E10.5 AGM, and was required in a dose- and timedependent manner to produce functional HSCs [41]. All those data indicate that Wnt signaling maybe not be decisive in direct control of HSCs fate, but it is crucial for the initial specification of HSCs.

\subsection{Bmp4 signaling}

Bone morphogenetic proteins (BMPs) acts as multifunctional growth factors and belongs to the transforming growth factor beta (TGF) superfamily, which regulate many cellular processes including cell fate determination during early embryonic development. The activation of signaling pathways begins with the heterodimerization of Type I and II receptors upon binding to Bmp ligands, which are followed by cytoplasmic R-Smads phosphorylation and in turn regulates multiple genes expression [42]. Signal transduction studies have revealed that Smad1, 5 and 8 are the immediate downstream proteins of Bmp receptors, and they play central roles in the pathway [43].

Bmp4 is a key determinant for the Runx1-mediated emergence of HSCs from hemogenic endothelium, as confirmed by a conditional knockdown assay in zebrafish that resulted in a loss of HSCs in the ventral wall of the dorsal aorta, while the arterial program was unaffected [44]. Recently, a novel PKA-cAMP response element-binding protein (CREB)-Bmp signaling pathway downstream of shear stress was proved to function in HSC emergence in the AGM through the endothelial-hematopoietic transition [45]. Knowing the regulation of downstream signals of the pathway is relatively more crucial. For years, studies conducted on cytoplasmic like Smad1, Smad5 and Smad9 confirmed that Bmp4 signal only functioned in HSC formation instead of later lineage commitment [46-48]. Interaction between Smad1/5 and extracellular signal-regulated kinase (ERK) signaling is essential for endothelial-hematopoietic transition, shown by the defects in HSC formation induced by ERK activation via knockdown of Smad1/5 [47]. These findings manifest the different requirements in Bmp signaling during hematopoietic commitment from endothelium.

\subsection{Other signals}

Multiple additional signals also influence the specification of HSCs from hemogenic endothelium. Studies in zebrafish have proved that Notch regulated HSC specification was directly controlled by Shh-VEGF signaling (vascular endothelial growth factor acts downstream of sonic hedgehog) during arterial endothelial differentiation [20,22]. A zebrafish study menifests that the FGF signaling regulates HSC fate through repressing BMP activity and this negative regulation is independent from arterial specification during the convergence of vascular precursor cells to the midline [49]. Meanwhile, it has been proved that Wnt16 acts upstream of FGF signaling pathway through FGF receptor 4 (Fgfr4) to relay signals to Notch ligand deltaC (dlc) in fate HSCs during the endothelial-hematopoietic transition process [50]. Recent works have uncovered several previously unknown signals required for HSC specification including the PGE2-cAMP/PKA signaling axis [51-53] which was activated by biomechanical forces, and the inflammatory signaling toll-like receptor 4 (TLR4)/nuclear factor-kappa B (NF- $\mathrm{BB})$ which regulates HSC determination via promoting Notch activity [54]. Advances in new signaling pathways that relates to the fate determination of HSCs may help improve the whole molecular patterns of certain precursor cells. Collectively, these findings indicate that the precursors of HSCs must emergence in time in the dorsal aorta to accept specified signals to fulfill the final specification step.

\subsection{Interactions of different signaling pathways}

The expression pattern of these required signals is dynamic in location and timing, which is closely related to their biological roles. As to HSC specification, direct cell-to-cell contact through Notch receptors and ligands in proper time is needed, so does those signals such as Bmp4 that function in somites. The interaction models of key signaling pathways that dominant HSC emergence from hemogenic endothelium both in vivo and in vitro can be concluded below (Figure 1). Canonical Wnt signaling also interact with other pathways, such as the PGE2, in a $\beta$-catenin-dependent manner [40]. Shh signaling induces vascular endothelial growth factor A (VegfA) expression in somites, which in turn activates the expression of Notch receptors in endothelial cells, thus promoting the possibility to activate Notch signaling in HSC specification [22]. FGF signaling function as an intermediate role in somites between Wnt16 and Notch signaling pathway in HSC specification from hemogenic endothelium. In conclusion, coordination between multiple signaling pathways leads to the inflexible time- and dose-dependent requirement of molecular signals during HSC specification.

\section{Summary}

Hematopoietic regulation is a complex dynamic network controlled by both intrinsic and extrinsic factors in a three 


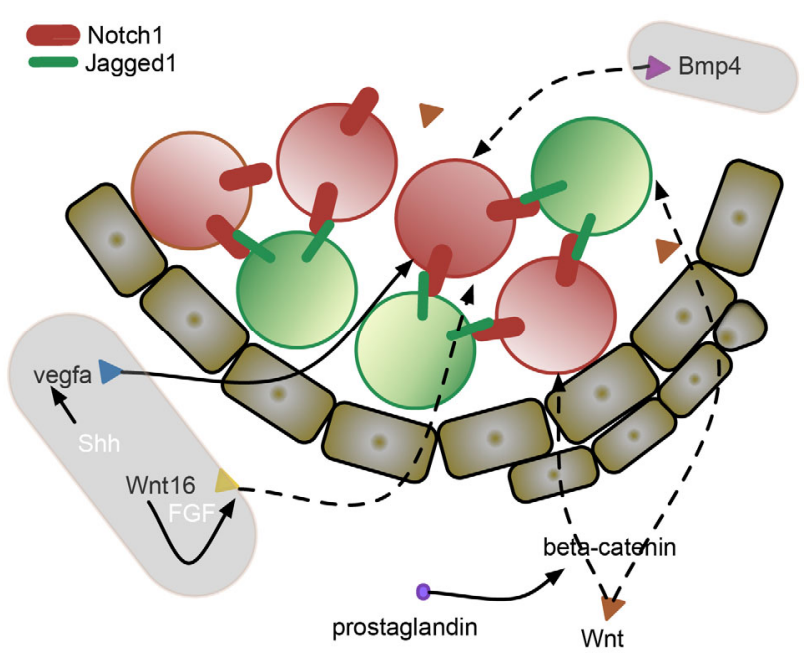

Figure 1 Major cell signaling pathways involved in HSC specification from hemogenic endothelium. In the dorsal aorta, hemogenic endothelium (Red) receives specified signals from adjacent cells (Green) and somites (Grey) to gain HSCs fate. Key molecular signals involved in this process include Notch; non-canonical/canonical Wnt; Shh; Bmp4. Solid lines indicate there are genetic evidence of interacting proteins, while dotted lines represent unproved but plausible interactions.

dimensional condition [55]. In recent years, efforts have been made in developing methods for producing specialized blood cells from hPSCs [56]. However, the clinical application of hPSCs derived blood cells such as the most promising red blood cells (RBCs) requires further development [57]. And when it comes to in vitro generation of HSCs, the most hopeful process is to define the direct precursors of HSCs in de novo systems. The fact that the embryonic vascular development is closely associated with HSC generation, which makes it vital to clarify the mechanical differences within these two processes. A recent study shown that genetic loss of Sox 17 and Notch1 (arterial genes) during EHT result in increased number of hematopoietic cells suggested that EHT is actively repressed in a sub set of endothelial cells [58].

As to hematopoietic differentiation of pluripotent stem cells (PSCs), signals such as Bmp4, VEGF, and Wnt have been used in combination with other factors in well-defined conditions in vitro to induce function hematopoietic progenitors. However, these approaches have not yet led to the formation of functional HSCs. The accumulating data have proved that not all of the hemogenic endothelial cells of in vitro systems can turn on definitive program $[59,60]$. The erythrocytes derived from hESC firstly show the primitive properties, then turn to obtain definitive properties in a clonal tracing assay, implying that there may be a definitive switching mechanism within hESC-derived hematopoiesis [61]. And a recent study also showed that hPSCs derived hemogenic endothelial cells are distinctive to in vivo studied hemogenic endothelium [62]. The existence of heterogeneous cell groups within HE cells, which cannot be identified simply by known cell surface markers, implys that more molecular mechanisms like the regulation of transcriptional and epigenetic factors (like Gata2 [63], Gata3 [64] and AML1 [65]) need to be re-discovered, so do the conserved signaling pathways which need to be reviewed. In this review, we have discussed a subset of known signaling pathways related to HSC specification from hemogenic endothelium. Upon combining with an efficient induction system as well as certain reporter hPSCs cell lines, the signaling pathways confirmed in animal studies need to be further tested in vitro, thus prompting the generation of HSCs in vitro. In summary, operating molecular networks such as signaling pathways will be the most promising method to explore the normal HSC development and finally to find ways to recapitulate it in vitro.

The author(s) declare that they have no conflict of interest.

This work was supported by the National Key Basic Research Program of China (2015CB964903), and the National Natural Science Foundation of China (81270640).

1 Bertrand JY, Cisson JL, Stachura DL, Traver D. Notch signaling distinguishes 2 waves of definitive hematopoiesis in the zebrafish embryo. Blood, 2010, 14: 2777-2783

2 de Bruijn MF, Speck NA, Peeters MC, Dzierzak E. Definitive hematopoietic stem cells first develop within the major arterial regions of the mouse embryo. Embo J, 2000, 11: 2465-2474

3 Gekas C, Dieterlen-Lievre F, Orkin SH, Mikkola HK. The placenta is a niche for hematopoietic stem cells. Dev Cell, 2005, 3: 365-375

4 Li Z, Lan Y, He W, Chen D, Wang J, Zhou F, Wang Y, Sun H, Chen X, Xu C, Li S, Pang Y, Zhang G, Yang L, Zhu L, Fan M, Shang A, Ju Z, Luo L, Ding Y, Guo W, Yuan W, Yang X, Liu B. Mouse embryonic head as a site for hematopoietic stem cell development. Cell Stem Cell, 2012, 5: 663-675

5 Samokhvalov IM, Samokhvalova NI, Nishikawa S. Cell tracing shows the contribution of the yolk sac to adult haematopoiesis. Nature, 2007, 7139: 1056-1061

6 Eilken HM, Nishikawa S, Schroeder T. Continuous single-cell imaging of blood generation from haemogenic endothelium. Nature, 2009, 7231: 896-900

7 Lancrin C, Sroczynska P, Stephenson C, Allen T, Kouskoff V, Lacaud G. The haemangioblast generates haematopoietic cells through a haemogenic endothelium stage. Nature, 2009, 7231: 892-895

8 Muller AM, Medvinsky A, Strouboulis J, Grosveld F, Dzierzak E. Development of hematopoietic stem cell activity in the mouse embryo. Immunity, 1994, 4: 291-301

9 Choi K, Kennedy M, Kazarov A, Papadimitriou JC, Keller G. A common precursor for hematopoietic and endothelial cells. Development, 1998, 4: 725-732

10 Winnier G, Blessing M, Labosky PA, Hogan BL. Bone morphogenetic protein-4 is required for mesoderm formation and patterning in the mouse. Genes Dev, 1995, 17: 2105-2116

11 Yamaguchi TP, Harpal K, Henkemeyer M, Rossant J. fgfr-1 is required for embryonic growth and mesodermal patterning during mouse gastrulation. Genes Dev, 1994, 24: 3032-3044

12 Conlon FL, Lyons KM, Takaesu N, Barth KS, Kispert A, Herrmann B, Robertson EJ. A primary requirement for nodal in the formation and maintenance of the primitive streak in the mouse. Development, 1994, 7: 1919-1928

13 Liu P, Wakamiya M, Shea MJ, Albrecht U, Behringer RR, Bradley A. Requirement for Wnt3 in vertebrate axis formation. Nat Genet, 1999, 4: 361-365

14 Boisset JC, van Cappellen W, Andrieu-Soler C, Galjart N, Dzierzak $\mathrm{E}$, Robin C. In vivo imaging of haematopoietic cells emerging from 
the mouse aortic endothelium. Nature, 2010, 7285: 116-120

15 Yokomizo T, Dzierzak E. Three-dimensional cartography of hematopoietic clusters in the vasculature of whole mouse embryos. Development, 2010, 21: 3651-3661

16 Li W, Ferkowicz MJ, Johnson SA, Shelley WC, Yoder MC. Endothelial cells in the early murine yolk sac give rise to CD41-expressing hematopoietic cells. Stem Cells Dev, 2005, 1: 44-54

17 Marcelo KL, Sills TM, Coskun S, Vasavada H, Sanglikar S, Goldie LC, Hirschi KK. Hemogenic endothelial cell specification requires c-Kit, Notch signaling, and P27-mediated cell-cycle control. Dev Cell, 2013, 5: 504-515

18 Bertrand JY, Chi NC, Santoso B, Teng S, Stainier DY, Traver D. Haematopoietic stem cells derive directly from aortic endothelium during development. Nature, 2010, 7285: 108-111

19 Sturgeon CM, Ditadi A, Awong G, Kennedy M, Keller G. Wnt signaling controls the specification of definitive and primitive hematopoiesis from human pluripotent stem cells. Nat Biotechnol, 2014, 6: 554-561

20 Gering M, Patient R. Hedgehog signaling is required for adult blood stem cell formation in zebrafish embryos. Dev Cell, 2005, 3: 389-400

21 Jang IH, Lu YF, Zhao L, Wenzel PL, Kume T, Datta SM, Arora N, Guiu J, Lagha M, Kim PG, Do EK, Kim JH, Schlaeger TM, Zon LI, Bigas A, Burns CE, Daley GQ. Notch1 acts via Foxc2 to promote definitive hematopoiesis via effects on hemogenic endothelium. Blood, 2015, 9: 1418-1426

22 Lawson ND, Vogel AM, Weinstein BM. Sonic hedgehog and vascular endothelial growth factor act upstream of the Notch Pathway during arterial endothelial differentiation. Dev Cell, 2002, 1: 127-136

23 Nostro MC, Cheng X, Keller GM, Gadue P. Wnt, activin, and BMP signaling regulate distinct stages in the developmental pathway from embryonic stem cells to blood. Cell Stem Cell, 2008, 1: 60-71

24 Kissa K, Herbomel P. Blood stem cells emerge from aortic endothelium by a novel type of cell transition. Nature, 2010, 7285: 112-115

25 Sturgeon CM, Ditadi A, Clarke RL, Keller G. Defining the path to hematopoietic stem cells. Nat Biotechnol, 2013, 5: 416-418

26 Artavanis-Tsakonas S, Rand MD, Lake RJ. Notch signaling: cell fate control and signal integration in development. Science, 1999, 5415: 770-776

27 Kopan R, Ilagan MX. The canonical notch signaling pathway: unfolding the activation mechanism. Cell, 2009, 2: 216-233

28 Burns CE, Traver D, Mayhall E, Shepard JL, Zon LI. Hematopoietic stem cell fate is established by the Notch-Runx pathway. Genes Dev, 2005, 19: 2331-2342

29 Yoon MJ, Koo BK, Song R, Jeong HW, Shin J, Kim YW, Kong YY, Suh PG. Mind bomb-1 is essential for intraembryonic hematopoiesis in the aortic endothelium and the subaortic patches. Mol Cell Biol, 2008, 15: 4794-4804

30 Kumano K, Chiba S, Kunisato A, Sata M, Saito T, Nakagami-Yamaguchi E, Yamaguchi T, Masuda S, Shimizu K, Takahashi T, Ogawa S, Hamada Y, Hirai H. Notch1 but not Notch2 is essential for generating hematopoietic stem cells from endothelial cells. Immunity, 2003, 5: 699-711

31 Hadland BK, Huppert SS, Kanungo J, Xue Y, Jiang R, Gridley T, Conlon RA, Cheng AM, Kopan R, Longmore GD. A requirement for Notch1 distinguishes 2 phases of definitive hematopoiesis during development. Blood, 2004, 10: 3097-3105

32 Kim AD, Melick CH, Clements WK, Stachura DL, Distel M, Panakova D, MacRae C, Mork LA, Crump JG, Traver D. Discrete Notch signaling requirements in the specification of hematopoietic stem cells. Embo J, 2014, 20: 2363-2373

33 Robert-Moreno A, Guiu J, Ruiz-Herguido C, Lopez ME, Ingles-Esteve J, Riera L, Tipping A, Enver T, Dzierzak E, Gridley T, Espinosa L, Bigas A. Impaired embryonic haematopoiesis yet normal arterial development in the absence of the Notch ligand Jagged1. Embo J, 2008, 13: 1886-1895

34 Logan CY, Nusse R. The Wnt signaling pathway in development and disease. Annu Rev Cell Dev Biol, 2004, 20: 781-810

35 Luis TC, Ichii M, Brugman MH, Kincade P, Staal FJ. Wnt signaling strength regulates normal hematopoiesis and its deregulation is involved in leukemia development. Leukemia, 2012, 3: 414-421

36 Staal FJ, Luis TC, Tiemessen MM. WNT signalling in the immune system: WNT is spreading its wings. Nat Rev Immunol, 2008, 8: 581-593

37 Clements WK, Traver D. Signalling pathways that control vertebrate haematopoietic stem cell specification. Nat Rev Immunol, 2013, 5: 336-348

38 Luis TC, Weerkamp F, Naber BA, Baert MR, de Haas EF, Nikolic T, Heuvelmans S, De Krijger RR, van Dongen JJ, Staal FJ. Wnt3a deficiency irreversibly impairs hematopoietic stem cell self-renewal and leads to defects in progenitor cell differentiation. Blood, 2009, 3: 546-554

39 Luis TC, Naber BA, Fibbe WE, van Dongen JJ, Staal FL. Wnt3a nonredundantly controls hematopoietic stem cell function and its deficiency results in complete absence of canonical Wnt signaling. Blood, 2010, 3: 496-497

40 Goessling W, North TE, Loewer S, Lord AM, Lee S, Stoick-Cooper CL, Weidinger G, Puder M, Daley GQ, Moon RT, Zon LI. Genetic interaction of PGE2 and Wnt signaling regulates developmental specification of stem cells and regeneration. Cell, 2009, 6: 1136-1147

41 Ruiz-Herguido C, Guiu J, D’Altri T, Ingles-Esteve J, Dzierzak E, Espinosa L, Bigas A. Hematopoietic stem cell development requires transient Wnt/beta-catenin activity. J Exp Med, 2012, 8: 1457-1468

42 Schmierer B, Hill CS. TGFbeta-SMAD signal transduction: molecular specificity and functional flexibility. Nat Rev Mol Cell Biol, 2007, 12: 970-982

43 Massague J, Wotton D. Transcriptional control by the TGF-beta/ Smad signaling system. Embo J, 2000, 8: 1745-1754

44 Wilkinson RN, Pouget C, Gering M, Russell AJ, Davies SG, Kimelman D, Patient R. Hedgehog and Bmp polarize hematopoietic stem cell emergence in the zebrafish dorsal aorta. Dev Cell, 2009, 6: 909-916

45 Kim PG, Nakano H, Das PP, Chen MJ, Rowe RG, Chou SS, Ross SJ, Sakamoto KM, Zon LI, Schlaeger TM, Orkin SH, Nakano A, Daley GQ. Flow-induced protein kinase A-CREB pathway acts via BMP signaling to promote HSC Emergence. J Exp Med, 2015, 5: 633-648

46 Blank U, Seto ML, Adams DC, Wojchowski DM, Karolak MJ, Oxburgh L. An in vivo reporter of BMP signaling in organogenesis reveals targets in the developing kidney. Bmc Dev Biol, 2008, 8: 86

47 Zhang C, Lv J, He Q, Wang S, Gao Y, Meng A, Yang X, Liu F. Inhibition of endothelial ERK signalling by Smad1/5 is essential for haematopoietic stem cell emergence. Nat Commun, 2014, 5: 3431

48 Singbrant S, Karlsson G, Ehinger M, Olsson K, Jaako P, Miharada K, Stadtfeld M, Graf T, Karlsson S. Canonical BMP signaling is dispensable for hematopoietic stem cell function in both adult and fetal liver hematopoiesis, but essential to preserve colon architecture. Blood, 2010, 23: 4689-4698

49 Pouget C, Peterkin T, Simoes FC, Lee Y, Traver D, Patient R. FGF signalling restricts haematopoietic stem cell specification via modulation of the BMP pathway. Nat Commun, 2014, 5: 5588

50 Lee Y, Manegold JE, Kim AD, Pouget C, Stachura DL, Clements WK, Traver D. FGF signalling specifies haematopoietic stem cells through its regulation of somitic Notch signalling. Nat Commun, 2014, 5: 5583

51 North TE, Goessling W, Peeters M, Li P, Ceol C, Lord AM, Weber GJ, Harris J, Cutting CC, Huang P, Dzierzak E, Zon LI. Hematopoietic stem cell development is dependent on blood flow. Cell, 2009, 4: 736-748

52 Adamo L, Naveiras O, Wenzel PL, McKinney-Freeman S, Mack PJ, Gracia-Sancho J, Suchy-Dicey A, Yoshimoto M, Lensch MW, Yoder MC, Garcia-Cardena G, Daley GQ. Biomechanical forces promote embryonic haematopoiesis. Nature, 2009, 7250: 1131-1135

53 Diaz MF, Li N, Lee HJ, Adamo L, Evans SM, Willey HE, Arora N, Torisawa YS, Vickers DA, Morris SA, Naveiras O, Murthy SK, Ingber DE, Daley GQ, Garcia-Cardena G, Wenzel PL. Biomechanical forces promote blood development through prostaglandin E2 and the cAMP-PKA signaling axis. J Exp Med, 2015, 5: 665-680 
54 He Q, Zhang C, Wang L, Zhang P, Ma D, Lv J, Liu F. Inflammatory signaling regulates hematopoietic stem and progenitor cell emergence in vertebrates. Blood, 2015, 7: 1098-1106

55 Liu S, Xu Y, Zhou Z, Feng B, Huang H. Progress and challenges in generating functional hematopoietic stem/progenitor cells from human pluripotent stem cells. Cytotherapy, 2015, 4: 344-358

56 Kaufman DS. Toward clinical therapies using hematopoietic cells derived from human pluripotent stem cells. Blood, 2009, 17: 3513-3523

57 Xie X, Li Y, Pei X. From stem cells to red blood cells: how far away from the clinical application? Sci China Life Sci, 2014, 6: 581-585

58 Lizama CO, Hawkins JS, Schmitt CE, Bos FL, Zape JP, Cautivo KM, Borges Pinto H, Rhyner AM, Yu H, Donohoe ME, Wythe JD, Zovein AC. Repression of arterial genes in hemogenic endothelium is sufficient for haematopoietic fate acquisition. Nat Commun, 2015, 6: 7739

59 Chen MJ, Li Y, De Obaldia ME, Yang Q, Yzaguirre AD, Yamada-Inagawa T, Vink CS, Bhandoola A, Dzierzak E, Speck NA. Erythroid/myeloid progenitors and hematopoietic stem cells originate from distinct populations of endothelial cells. Cell Stem Cell, 2011, 6 : $541-552$

60 Rafii S, Kloss CC, Butler JM, Ginsberg M, Gars E, Lis R, Zhan Q, Josipovic P, Ding BS, Xiang J, Elemento O, Zaninovic N, Rosen- waks Z, Sadelain M, Rafii JA, James D. Human ESC-derived hemogenic endothelial cells undergo distinct waves of endothelial to hematopoietic transition. Blood, 2013, 5: 770-780

61 Ma F, Ebihara Y, Umeda K, Sakai H, Hanada S, Zhang H, Zaike Y, Tsuchida E, Nakahata T, Nakauchi H, Tsuji K. Generation of functional erythrocytes from human embryonic stem cell-derived definitive hematopoiesis. Proc Natl Acad Sci USA, 2008, 35: 13087-13092

62 Ditadi A, Sturgeon CM, Tober J, Awong G, Kennedy M, Yzaguirre AD, Azzola L, Ng ES, Stanley EG, French DL, Cheng X, Gadue P, Speck NA, Elefanty AG, Keller G. Human definitive haemogenic endothelium and arterial vascular endothelium represent distinct lineages. Nat Cell Biol, 2015, 5: 580-591

63 Suzuki N, Ohneda O, Minegishi N, Nishikawa M, Ohta T, Takahashi S, Engel JD, Yamamoto M. Combinatorial Gata2 and Sca1 expression defines hematopoietic stem cells in the bone marrow niche. Proc Natl Acad Sci USA, 2006, 7: 2202-2207

64 Fitch SR, Kimber GM, Wilson NK, Parker A, Mirshekar-Syahkal B, Gottgens B, Medvinsky A, Dzierzak E, Ottersbach K. Signaling from the sympathetic nervous system regulates hematopoietic stem cell emergence during embryogenesis. Cell Stem Cell, 2012, 4: 554-566

65 Okuda T, van Deursen J, Hiebert SW, Grosveld G, Downing JR. AML1, the target of multiple chromosomal translocations in human leukemia, is essential for normal fetal liver hematopoiesis. Cell, 1996, 2: $321-330$

Open Access This article is distributed under the terms of the Creative Commons Attribution License which permits any use, distribution, and reproduction in any medium, provided the original author(s) and source are credited. 